\title{
Synthesis, structural study, biological and NLO properties of three new hybrid compounds of dapsone
}

\author{
Amani Hind Benahsene ${ }^{1}$, Lamia Bendjeddou ${ }^{1}$, Rokaya Henchiri $^{2}$, Nasreddine Ennaceur ${ }^{2}$ \\ ${ }^{1}$ Unitéde Recherche de Chimie de l'Environnement et MoléculaireStructurale (URCHEMS), Université Frères Mentouri Constantine, \\ Route Ain Elbay 25000, Constantine, Algérie \\ ${ }^{2}$ Laboratory of Materials, Energy and Environment UR14-ES26, University of Gafsa, 2100 Gafsa, Tunisia. \\ ${ }^{3}$ Laboratory of Quantum and Molecular Photonics, Institut d'Alembert, École normale supérieure Paris-Saclay, 94230 Cachan, \\ France
}

Hybrid organic-inorganic compounds are receiving considerable attention in recent years due to the possibility of combining the different characteristics of the components to get unusual and enormous variety of interesting structural topologies and wide potential applications in the fields of catalysis, non-linear optics, sensors, magnetism and molecular recognition ${ }^{[1]}$. During our investigation, we synthesized three new hybrid organic-inorganic compounds of dapsone with antibacterial and second-order nonlinear optical properties ${ }^{[2]}$. The structural study and Hirshfeld surface analysis allowed us to establish the importance of hydrogen bond and intermolecular interaction in the crystal packing.and their role in the NLO properties.
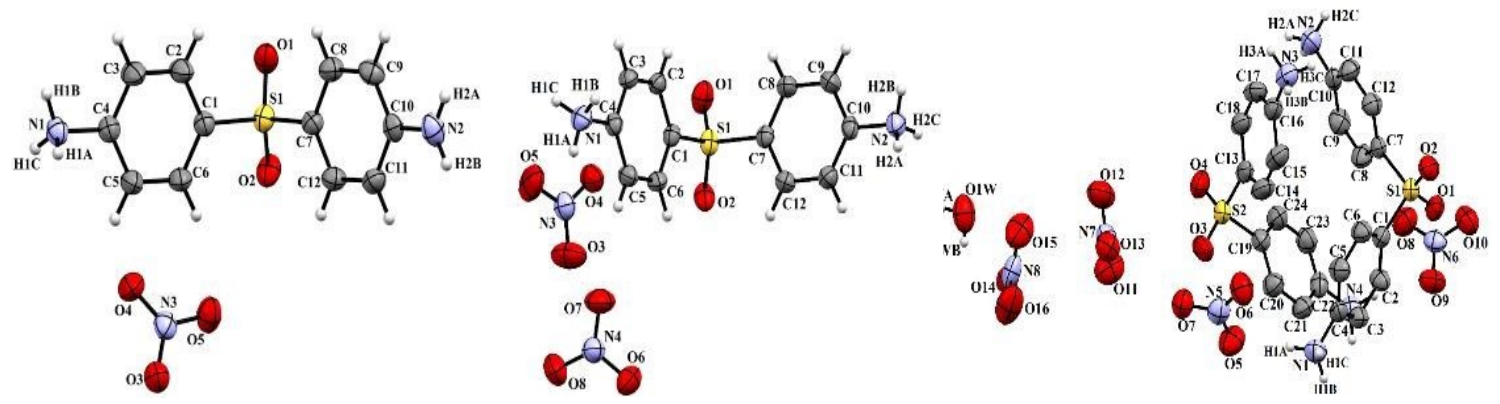

Fig.1: Asymmetric unit of the three hybrid organic-inorganic compounds

[1] O.M. Yaghi, H. Li, T.L. Groy, J. Am. Chem. Soc. 118 (1996) 9096

[2] Prasad, P. N.; Williams, D. J. Introduction to Nonlinear Optical Effects in Molecules and Polymers; John Wiley \& Sons: New York, 1991.

Keywords: NLO, Hydrogen bonds, DDS ligand 